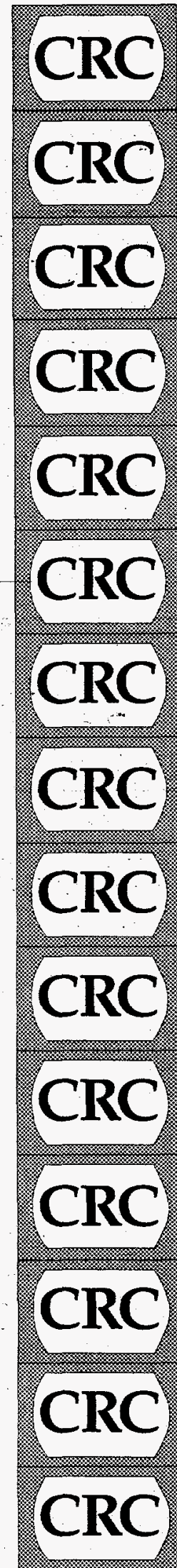

OSTI

$-1$

DOE/EW//2823--T

Flow and Transport Model of the

Savannah River Site Old Burial Grounds

Using Data Fusion Modeling (DFM)

..... November 1995

Prepared for

Department of Energy

EM-50

Prepared by

Coleman Research Corp

9891 Broken Land Parkway

Columbia, MD 21046

$301.621-8600$

HydroGeoLogic Inc.

1165 Herndon Parkway

Herndon, VA 22070 703 - $478-5186$

\title{
Coleman Research Corporation
}

HIGH TECHNOLOGY AEROSPACE SYSTEMS DESIGN

ORLANDO HUNTSVILLE WASHINGTON, D.C. EL PASO

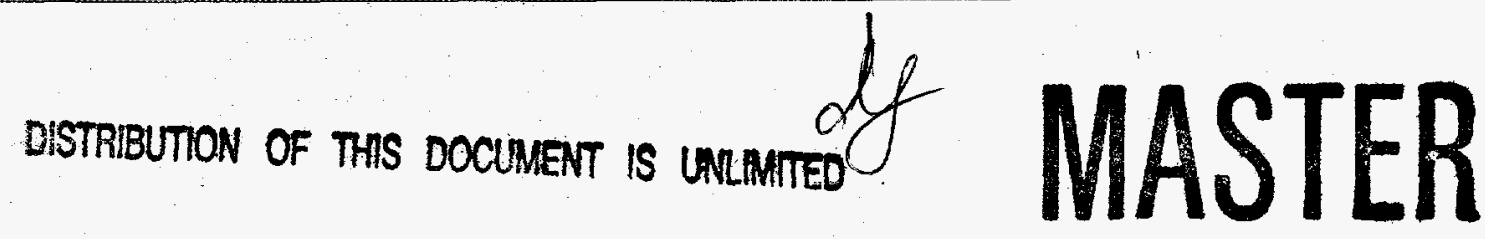


Flow and Transport Model of the Savannah River Site Old Burial Grounds Using Data Fusion Modeling (DFM)

November 1995

\author{
Prepared for \\ Department of Energy \\ EM-50 \\ Prepared by
}

Coleman Research Corp 9891 Broken Land Parkway

Columbia, MD 21046 $301621-8600$

HydroGeoLogic Inc. 1165 Herndon Parkway Hernidon, VA 22070 703 478-5186 


\section{DISCLAIMER}

This report was prepared as an account of work sponsored by an agency of the United States Government. Neither the United States Government nor any agency thereof, nor any of their employees, make any warranty, express or implied, or assumes any legal liability or responsibility for the accuracy, completeness, or usefulness of any information, apparatus, product, or process disclosed, or represents that its use would not infringe privately owned rights. Reference herein to any specific commercial product, process, or service by trade name, trademark, manufacturer, or otherwise does not necessarily constitute or imply its endorsement, recommendation, or favoring by the United States Government or any agency thereof. The views and opinions of authors expressed herein do not necessarily state or reflect those of the United States Government or any agency thereof. 


\section{DISCLAIMER}

Portions of this document may be illegible in electronic image products. Images are produced from the best available original document. 


\section{Introduction}

The Data Fusion Modeling (DFM) approach has been used to develop a groundwater flow and transport model of the Old Burial Grounds (OBG) at the U. S. Department of Energy's Savannah River Site (SRS). The resulting DFM model was compared to an existing model that was calibrated via the typical trial-and-error method [3]. The OBG was chosen because a substantial amount of hydrogeologic information is available, a FACT (derivative of VAM3DCG) [5] flow and transport model of the site exists, and the calibration and numerics were challenging with standard approaches. The DFM flow model developed here is similar to the flow model by Flach et al. [2]. This allows comparison of the two flow models and validates the utility of DFM.

The Savannah River Site occupies.approximately $800 \mathrm{~km}^{2}$ along the Savannah River in southwestern South Carolina. Since 1950 SRS has been a controlled area for the production of nuclear material for national defense and civilian purposes. The OBG is located in the central portion of SRS within the $40 \mathrm{~km}^{2}$ General Separations Area (GSA) (Fig: 1). The OBG is the original solid radioactive and hazardous waste burial ground in the GSA. Solid waste was deposited in the OBG from 1952 to 1972 . Groundwater contaminants of concern at the OBG include tritium, trichloroethylene (TCE) and tetrachloroethylene (PCE). Groundwater plumes emanating from the OBG are migrating to the south toward Fourmile Branch [3]. The contaminant of interest for this study is tritium, because it is a geochemically conservative tracer that has been monitored along the seepline near the F-Area effluent and Fourmile Branch for several years. Flach et al. [3] discussed the lithostratigraphy and hydrostratigraphy of the OBG. Figure 2 shows the classical layer-cake hydrostratigraphy that has been used in the past in the vicinity of the OBG.

The development of the DFM flow and transport model of the OBG relied heavily upon the work of WSRC [1], Flach et al. [2] and Flach [3]. WSRC [1] presented the hydrogeologic information on the OBG and developed the FACT flow model. In [1], detailed lithologic data was used to construct an extremely heterogeneous conductivity field versus the typical layer cake approach that had been utilized in the past (e.g., Geotrans, 1993 [4]). Flach [2] presented a model of the OBG tritium source, which was used in the transport simulations for this study. In addition, Monte Carlo analysis was performed to quantify the uncertainty in tritium transport.

\section{DFM Flow model}

\section{Numerical Grid and Boundary Conditions}

The numerical grid is a three-dimensional curvilinear grid with an areal extent of 6760 $\mathrm{ft}$ in the $\mathrm{x}$-direction and $5070 \mathrm{ft}$ in the $\mathrm{y}$-direction (Figure 3). The grid is $27 \times 27 \times 21$ with uniform spacing along the $x$ and $y$ axis. This is the same region considered in [1], but a $53 \times 40 \times 30$ grid was used. Figure 3 shows an areal view of the grid overlaid on the local- 


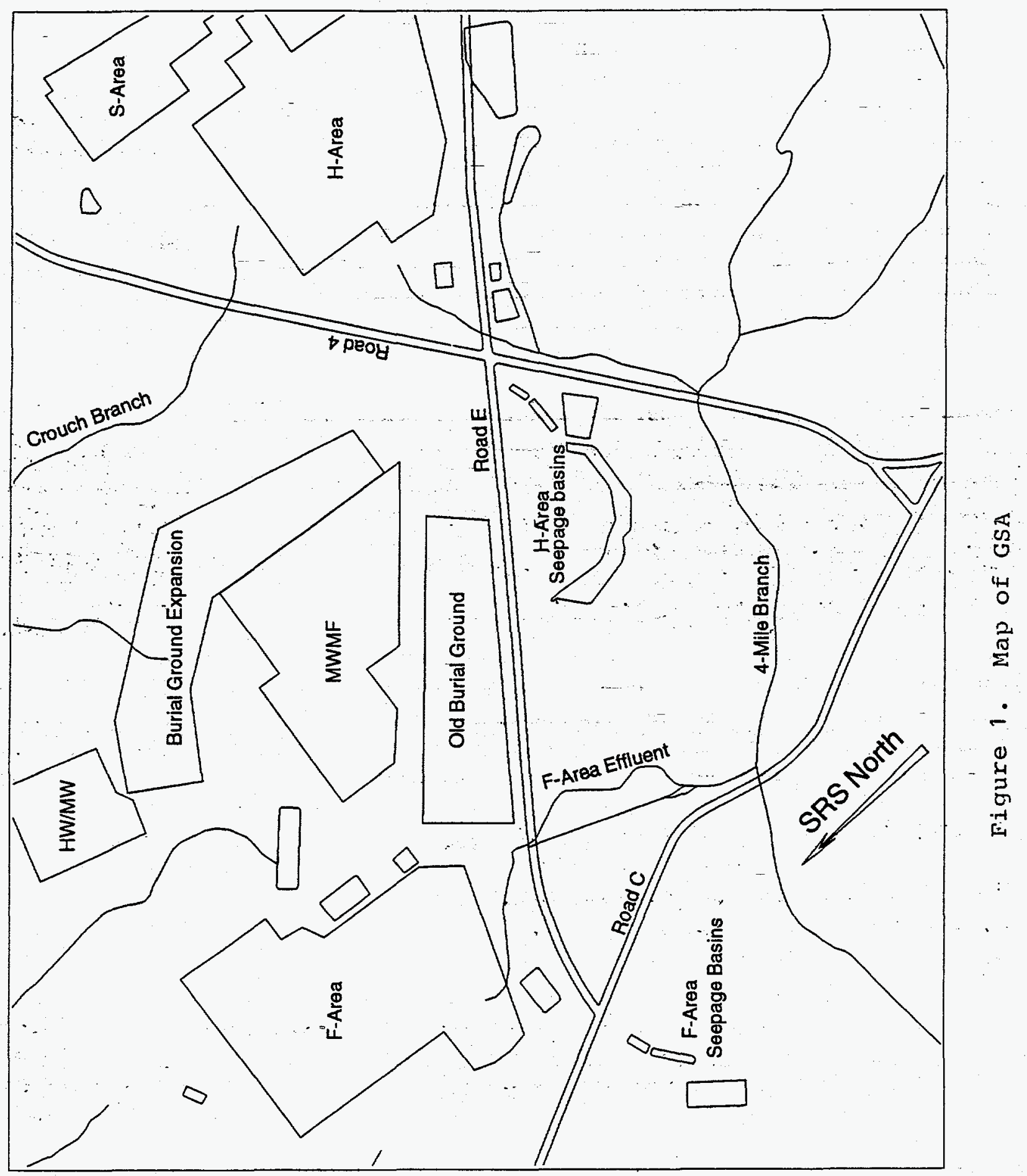




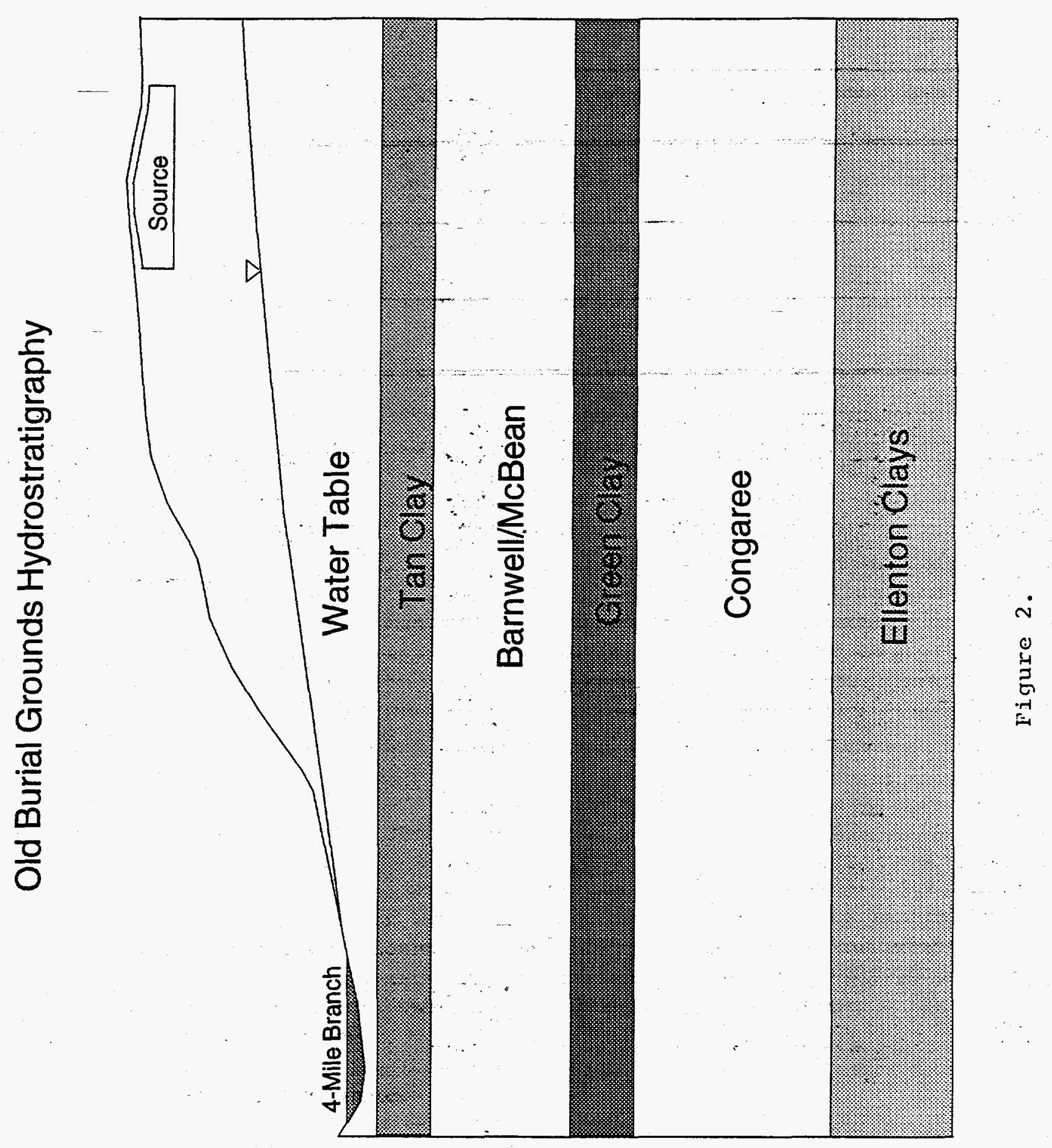


basemap. Hydrostratigraphic picks obtained from WSRC were used to define the elevation of the 21 nodal layers, so that each nodal layer was assigned to a only one aquifer unit. The upper nodal layer conformed to the land surface while the bottom nodal layer conformed to the top of the Ellenton Clays, which is a regional aquitard at the SRS. The Green Clay was discretized by the fourth nodal layer from the bottom.

The boundary conditions applied to DFM flow model are very similar to boundary conditions in [1]. The recharge/drain boundary condition [1] was applied to the top nodal layer and the no-flow boundary condition was applied to the interior nodes of the bottom nodal layer, which roughly approximates a no-flow condition across the Ellenton. All other boundary nodes were assigned constant head boundary conditions. Heads from observation wells were used to construct an areal two-dimensional head distribution for the Water Table, Barnwell/McBean and Congaree Aquifers. These three head distributions were used to define the constant head boundary conditions. Figure 4 illustrates the boundary conditions used.

\section{Head and Conductivity Data}

Heads from 237 observation wells (found in [1]) were calibration targets for the DFM flow model. In order to facilitate a comparison between the DFM flow model and the flow model in [1], a portion of the conductivity field of [1] was used as conductivity data. In [1], mud fraction data from the foot-by-foot description of 84 cores were interpolated on to a finescale three-dimensional grid $(23 \times 23 \times 251)$. The fine-scale mud fraction was mapped to horizontal conductivity $\left(\mathrm{K}_{\mathrm{h}}\right)$ and vertical conductivity $\left(\mathrm{K}_{\mathrm{v}}\right)$ using an empirical function. The fine-scale conductivities on the $23 \times 23 \times 251$ grid were then converted to the coarser $53 \times 40 \times 30$ grid using arithmetic $\left(\mathrm{K}_{\mathrm{h}}\right)$ and harmonic $\left(\mathrm{K}_{\mathrm{v}}\right)$ averaging. Of the 84 cores used in interpolation, 27 lay inside the OBG model. The conductivities above the Green Clay at the 27 interior core locations of the $53 \times 40 \times 30$ grid were used as conductivity estimates for the DFM flow model. Both the vertical and horizontal conductivities were used as measurements. A total of 880 conductivity estimates were used with 415 being horizontal conductivities and 465 being vertical conductivities.

\section{Parameters Estimated in DFM}

The spatial continuity (heterogeneity) model for hydraulic conductivity is applied to each hydrostratigraphic layer separately in the DFM. Thus the fusion OBG model consisted of three hydrostratigraphic layers. Layer 1 contained all nodes above the Green Clay. Layer 2 contained the fourth nodal layer from the bottom, which represented the Green Clay. Layer 3 contained the bottom three nodal layers, which represented the Congaree Aquifer and the top of the Ellenton Clays.

Head and log horizontal conductivity $\left(\ln \left(\mathrm{K}_{\mathrm{h}}\right)\right)$ were estimated at each node in the model where $\ln \left(\mathrm{K}_{\mathrm{h}}\right)$ is treated as a spatial random field. The user specifies the standard deviation and $3 \mathrm{D}$ correlation distances (distance at which correlation $=1 / e$ ) for $\ln \left(\mathrm{K}_{\mathrm{h}}\right)$ for each hydrostratigraphic layer. Also input are coefficients of the polynomial model defining the mean trend for $\ln \left(\mathrm{K}_{\mathrm{h}}\right)$ within each layer, since those coefficients- are estimated. The prior standard deviation for each polynomial coefficient is also specified by the user. In the OBG. 


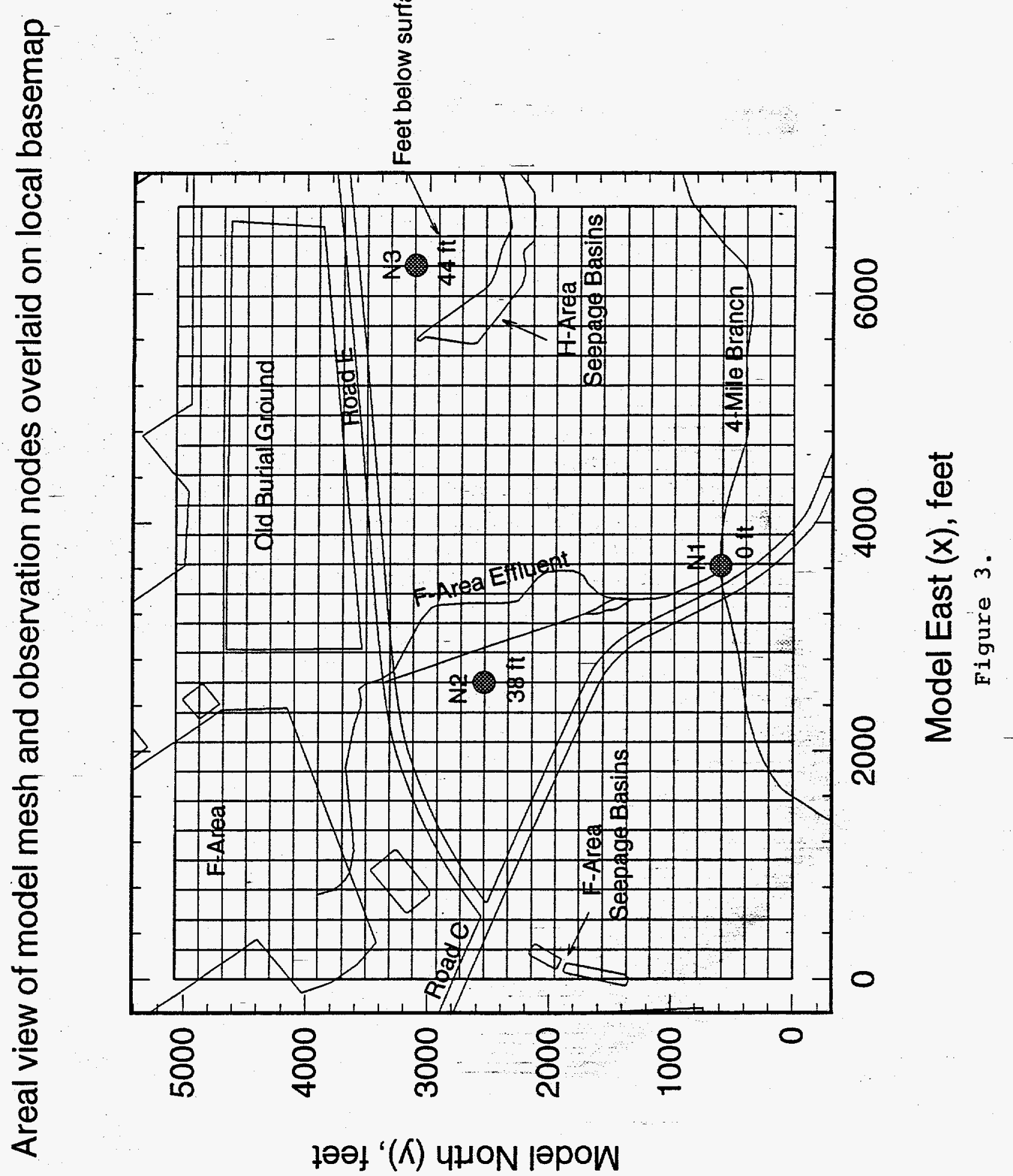




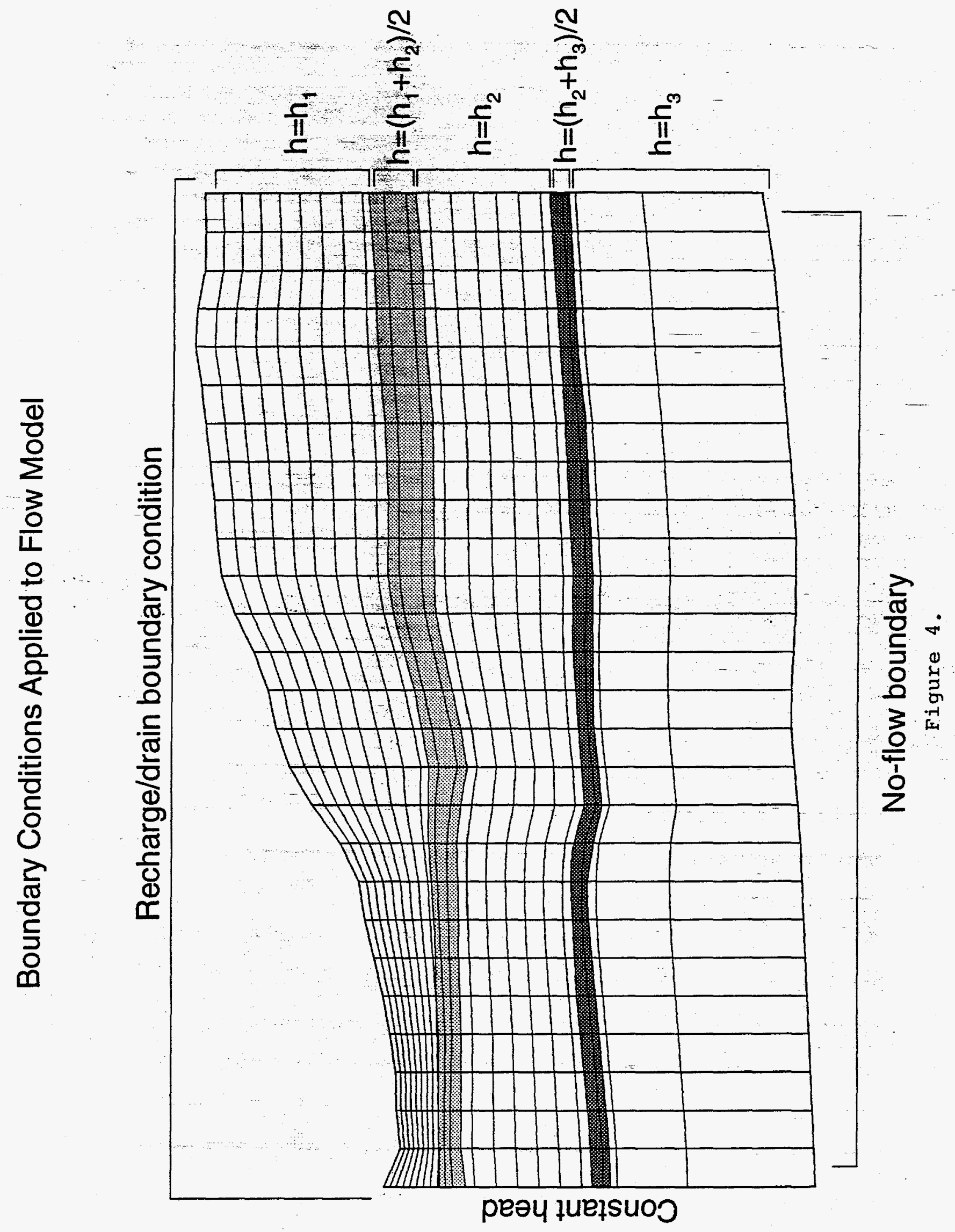


case, there did not appear to be a significant change in the trend across the OBG, so the trend model was limited to a constant (mean).

The DFM software allows considerable flexibility in specifying and estimating vertical hydraulic conductivity: $\log$ anisotropy can be defined by a spatial polynomial in a hydrostratigraphic unit, or vertical conductivity can be defined for specified zones (sets of nodes). In either case, the coefficients can be fixed or estimated separately for each zone. Within hydrostratigraphic layer 1 , the vertical anisotropy was initially defined using a linear 3D polynomial ( 4 coefficients), but the estimated linear coefficients were small, so the anisotropy model was reduced to a constant. The vertical conductivity in the tan clay was defined separately and is discussed below. In hydrostratigraphic layer 2 (Green clay), vertical conductivity was estimated directly, rather than using anisotropy. This was done because vertical flow dominates in aquitards and thus the relation between vertical and horizontal conductivity would not be observable from the data. Finally, the anisotropy in layer 3 (Congaree) was fixed at 3 , since there is little well information in this layer.

In addition to conductivity parameters, the maximum recharge coefficient was also estimated in the DFM. This "maximum recharge coefficient" is the maximum allowed recharge at an unsaturated surface node as used in a recharge/drain boundary coundition. This must be estimated because is has a strong influence on the flow model.

\section{Parameter Prior Statistics}

Table 1 lists the prior means and standard deviations used for parameters estimated in the OBG data fusion modeling. The values used for the means were based on information in reference 1. Standard deviations were selected as reasonable estimates for the variation in the parameters, with some modifications if the data would not support estimation of a parameter (e.g. the standard deviation of the Green clay $\ln (\mathrm{Kh})$ random component was set to 0.01). 
Table 1 - Prior on Conductivity (log $\mathrm{ft} /$ day)

\begin{tabular}{|c|c|c|c|c|c|c|c|c|c||}
\hline & \multicolumn{2}{|c|}{$\ln (\mathrm{Kh})$ trend } & \multicolumn{2}{|l|}{$\ln (\mathrm{Kh})$ heterogeneity } & \multicolumn{2}{|l|}{$\ln (\mathrm{Kv} / \mathrm{Kh})$} & \multicolumn{2}{c|}{ Ln(Kv) } \\
\cline { 2 - 10 } $\begin{array}{c}\text { Hydrostratigraphic } \\
\text { Layer }\end{array}$ & mean & 1 -sigma & 1-sigma & hor (ft). vert. (fr) & mean & 1-sigma & mean & 1-sigma \\
\hline $\begin{array}{c}\text { 1-Water table/ } \\
\text { Barnwell-Mcbean }\end{array}$ & 1.70 & 0.30 & 0.50 & 1000 & 20 & 4.0 & 0.3 & - & - \\
\hline 2-Green clay & -10.414 & 0.20 & 0.01 & 1000 & 100 & - & - & -12.21 & 0.30 \\
\hline 3-Congaree & 3.689 & 0.30 & 0.3 & 1000 & 50 & 1.1 & - & - & - \\
\hline
\end{tabular}

The prior information used for the maximum recharge coefficient was mean $=17.0$ in/year and standard deviation $=0.88 \mathrm{in} /$ year. Developed or capped areas used a coefficient of zero. Other input parameters included an effective porosity of 0.25 and a residual saturation used in the pseudo-soil function of 0.01 .

The steady-state flow error at each node is treated in the DFM as a pseudo-measurement which should nominally be zero. This flow error is included in the quadratic cost function, along with the actual measurement residuals and the spatial continuity pseudo-measurement residuals. This cost function is minimized as a nonlinear least squares problem. Since the flow error is treated as pseudo-measurement rather than a constraint, it must be weighted heavily. The error in the Green clay was weighted more heavily than that in other layers because of the very small vertical flow.

\section{Incorporating the Tan Clay}

Flach et al. [3] discussed how mud fraction data from 84 cores in GSA were used to construct a conductivity field on a $53 \times 40 \times 30$ grid. FORTRAN code was acquired from Westinghouse Savannah River Company (WSRC) for construction of the conductivity field on the $27 \times 27 \times 21$ grid. Nodes in the vicinity of the Tan Clay with $\mathrm{K}_{\mathrm{v}}<=0.0025 \mathrm{ft} /$ day were identified as Tan Clay nodes. For these Tan Clay nodes, $\ln \left(\mathrm{K}_{\mathrm{v}}\right)$ was set equal to $-8.0 \ln (\mathrm{ft} /$ day) in the data fusion flow model.

\section{DFM Parameter Estimates}

The VAM3DF flow model option of DFM was used to compute the steady-state flow errors at the nodes. The LSQR algorithm was used to compute the Gauss-Newton steps until convergence was achieved, since this is computationally much faster than the direct method (SRIF). However, LSQR does not compute the square root information matrix (R) required 
for covariance and transport uncertainty analysis. Thus a final DFM iteration was computed using the SRIF, and the R matrix was saved for later use. The resulting DFM estimated heads and horizontal conductivities are shown in Figures 5 and 6, respectively.

Because the conductivity correlation distances input to the DFM were relatively large, the DFM estimated conductivity field is smoother than the conductivity field in [1], but has similar trends. Figure 7 shows an areal view of three-dimensional pathlines. The pathlines originating near the OBG start in the vadose zone, travel through the saturated zone and discharge on the top of the model near Fourmile Branch. The DFM pathlines from the OBG to the F-Area effluent are similar to the pathlines presented by WSRC [1]. Also, the seeplines surrounding Fourmile Branch and the F-Area effluent are similar to the seeplines in [1]. The main difference between the two flow models is that the water divide (plane at which the flow separates) below the OBG is further south (closer to Fourmile Branch) in the fusion model, which is due to the lower (on average) horizontal conductivities in the water table aquifer of the data fusion model. There are also fine-scale differences in the velocity field, which are due to differences in the conductivity fields.

Estimated values of the hydraulic conductivity parameters are shown in Table 2. Note that most of the parameter estimates are close to the prior values, except for mean $\ln (\mathrm{Kh})$ in the upper layer, which is slightly higher, and $\ln (\mathrm{Kv})$ in the Green clay, which is slightly smaller.

Table 2 - DFM Estimated Conductivity Parameters (ln ft/day)

\begin{tabular}{|c|c|c|c|c|c|c||}
\hline \multirow{2}{*}{- Layer } & \multicolumn{2}{|c|}{$\ln (\mathrm{Kh})$ trend } & \multicolumn{2}{c|}{$\ln (\mathrm{Kv} / \mathrm{Kh})$} & \multicolumn{2}{c|}{$\ln (\mathrm{Kv})$} \\
\cline { 2 - 7 } & mean & 1 -sigma & mean & 1-sigma & mean & 1-sigma \\
\hline \hline $\begin{array}{c}\text { 1-Water table/ } \\
\text { Barnwell-Mcbean }\end{array}$ & 1.87 & 0.09 & 3.74 & 0.10 & - & - \\
\hline 2-Green clay & -10.42 & 0.20 & - & - & -13.57 & 0.20 \\
\hline 3-Congaree & 3.69 & 0.30 & - & - & - & - \\
\hline
\end{tabular}

The DFM estimated maximum recharge was $15.31 \mathrm{in} / \mathrm{yr}$ with an a posteriori 1-sigma uncertainty of $0.67 \mathrm{in} /$ year. This flow model computed a discharge to Fourmile Branch of $119,773 \mathrm{ft}^{3} /$ day $\left(1.4 \mathrm{ft}^{3} / \mathrm{sec}\right.$ ) and the average recharge (total volumetric inflow / area of the top of the model) was $12.3 \mathrm{in} / \mathrm{yr}$. In WSRC [1], the maximum recharge was set equal to $17 \mathrm{in} / \mathrm{yr}$. The resulting discharge to Fourmile Branch was $233,280 \mathrm{ft}^{3} /$ day and the average recharge was $13.55 \mathrm{in} / \mathrm{yr}$. Thus the DFM estimate of discharge is closer to previous estimates (based on measurements) of $151,000 \mathrm{ft}^{3} /$ day.

The a posteriori estimate error standard deviations for most of the nodal heads in the central 


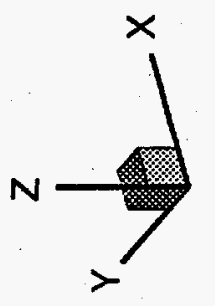

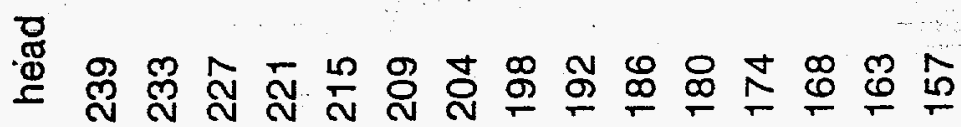

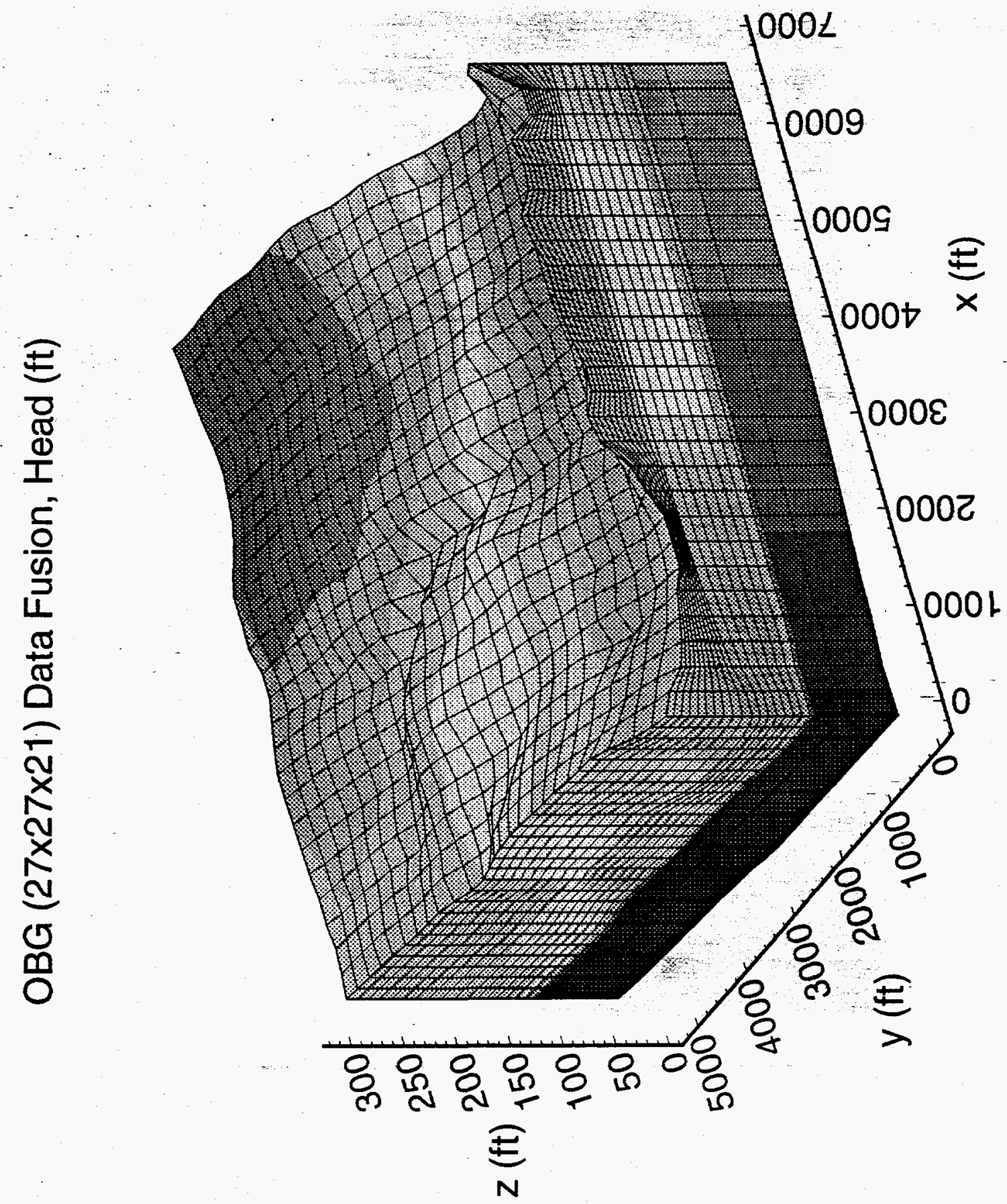




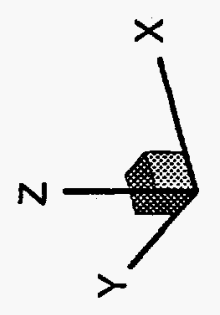

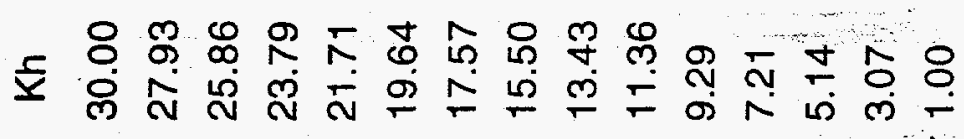

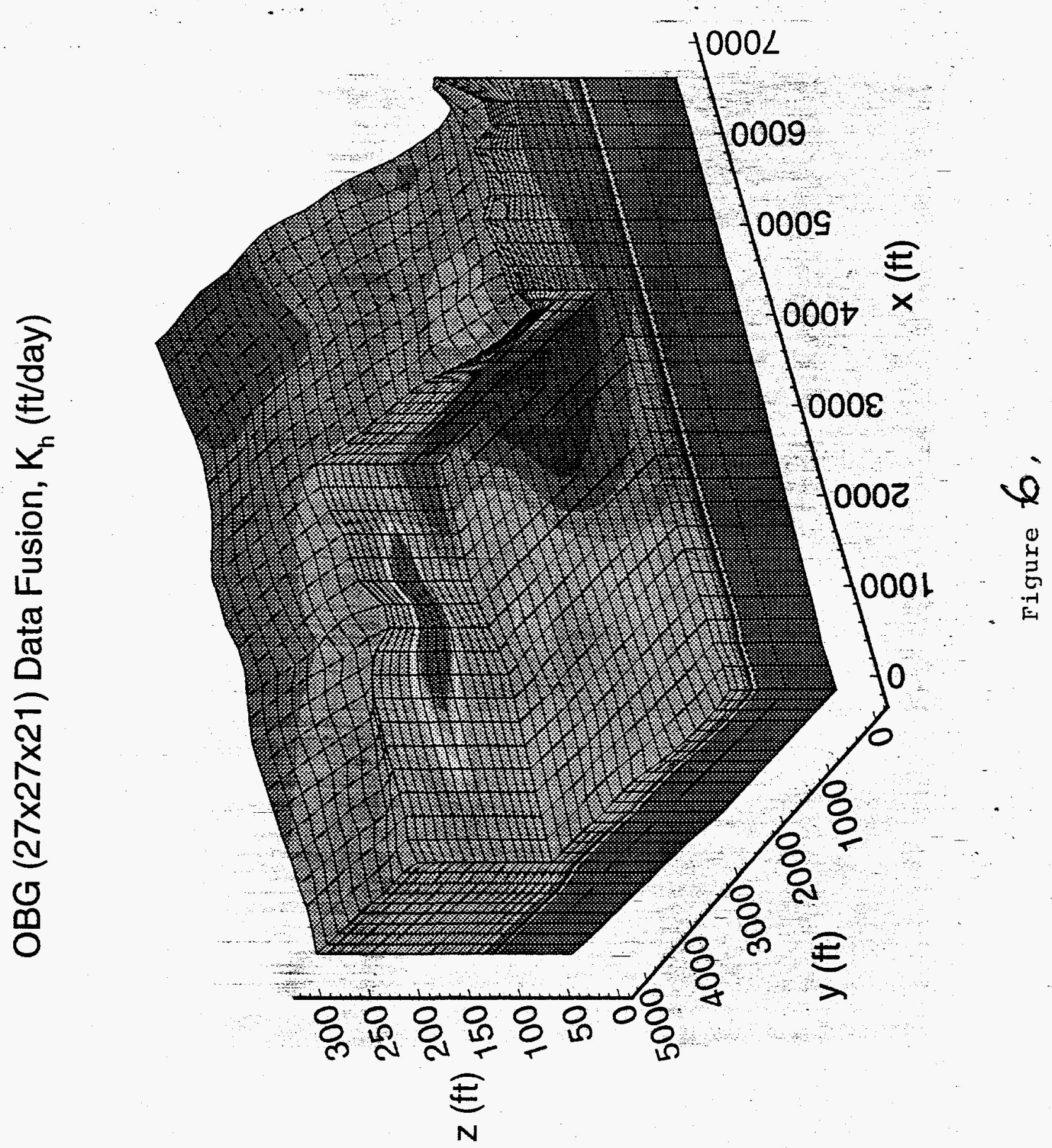




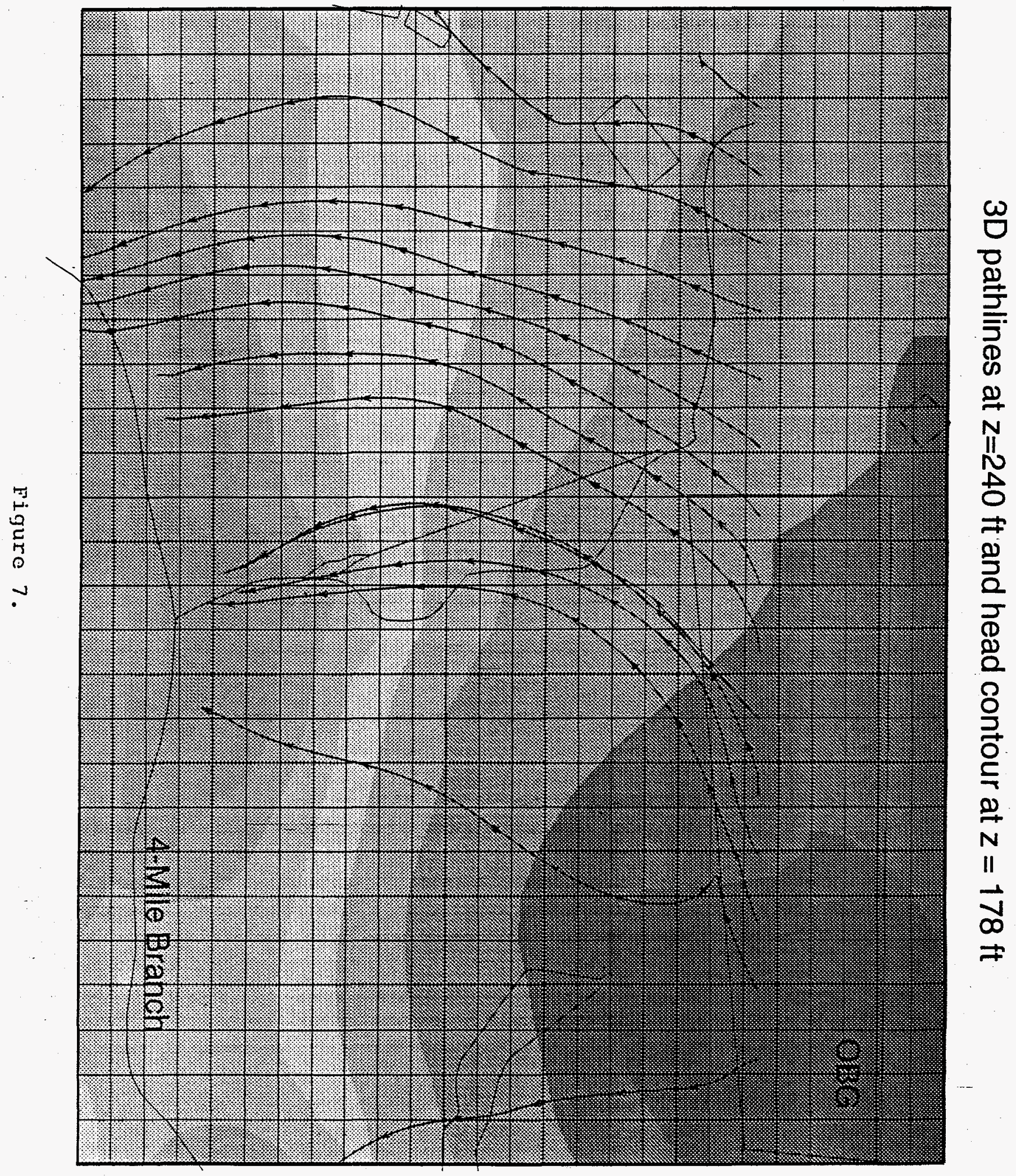


region in layer 1 were about 0.20 to 0.30 feet. The corresponding nodal $\ln (\mathrm{Kh})$ uncertainty was about 0.35 to 0.40 , which is somewhat smaller than the prior 1-sigma of 0.58 (including trend and heterogeneity), but is still significant. In addition to computing estimate error standard deviations, the DFM also computes the correlations between states. Surprisingly, very few correlation coefficients were greater than 0.3 , except for the conductivity parameters within the Green clay or Congaree (where little data was available). The most significant correlations were between the layer 1 anisotropy and the heads at the nodes near Four Mile branch. There was also significant correlation between recharge and the conductivities in the same region. This correlation is expected because the discharge of water gained by the system through recharge is strongly influenced by $\mathrm{Kv}$ near the stream.

\section{Residuals and Edited Data}

The DFM software edits any measurements for which the normalized residual (residual divided by nominal accuracy) is greater than a user specified threshold multiplying the root-meansquared (RMS) normalized residual from the previous iteration. The user must also input an initial residual RMS to use on the first iteration. Thus the editing threshold is very high on early iterations and becomes gradually smaller in later iterations as the fit to the data improves. The editing threshold used in the OBG modeling was set equal to 4.0 and the initial residual RMS was set to 200.0. At the final iteration, the residual RMS was 1.7 with 1117 measurements processed.

The cost function minimized in the DFM optimization includes three components: measurement residuals, pseudo-measurement residuals (both flow error and spatial continuity) and the residuals between posteriori and prior estimates. The normalized residual sum-ofsquares for the three components of the OBG fusion model were:

$$
\begin{array}{lcl}
\text { prior: } & 33.3 & (15) \\
\text { pseudo-measurements: } & 572.1 & (30618) \\
\text { measurements: } & 3095.0 & (1117)
\end{array}
$$

where the number of scalar components is listed in parentheses. Note that the model can effectively match the prior estimates and the pseudo-measurements, but has some difficulty in matching the measurements (primarily conductivity). However a normalized measurement residual RMS of 1.7 indicates that the measurement errors are only slightly larger than the expected accuracy. 
The following head measurements were rejected (determined to be outliers and not weighted in the solution):

\begin{tabular}{lcc} 
Well name & $\begin{array}{c}\text { DFM Model } \\
\text { Data }- \text { Model }(\mathrm{ft})\end{array}$ & $\begin{array}{c}\text { WSRC Model } \\
\text { Data }- \text { Model }(\mathrm{ft})\end{array}$ \\
\cline { 1 - 2 } S-15 & 6.6 & $\frac{8.2}{4}$ \\
FCB 3 & -4.5 & -5.2 \\
S-5 & 5.2 & 9.3 \\
U-13 & 5.6 & 10.6 \\
FTF 1 & 4.2 & 4.9 \\
HSB142C & -4.1 & -4.7 \\
HSB129C & -6.0 & -5.8 \\
HSB130D & -7.7 & -1.5 \\
MGC 32 & 7.0 & $\cdots$
\end{tabular}

Data fusion accepted 228 head measurements with a RMS of $1.3 \mathrm{ft}, 415$ horizontal conductivity estimates with a RMS of $1.3 \ln (\mathrm{ft} /$ day), and 465 vertical conductivity estimates with a RMS of $3.0 \ln (\mathrm{ft} /$ day $)$. For the flow model developed in [1], the RMS for the 228 accepted head measurements was $3.0 \mathrm{ft}$.

\section{Tritium Transport Uncertainty via Monte Carlo Analysis}

To quantify the effects of recharge, conductivity, and source uncertainty on tritium transport, a Monte Carlo transport simulation was used to compute the distribution of tritium concentration at specified locations. For each Monte Carlo trial, the DFM estimate of the flow states (nodal heads, $\log$ conductivities, anisotropy, $\ln (\mathrm{Kv})$ and recharge) was used as the sample mean, and a random perturbation consistent with the fusion error covariance was added. (This is done by backsolving using the SRIF $R$ matrix and a Gaussian random vector as the right-hand-side). Thus the flow state sample realizations have the mean and covariance expected from the flow modeling. The nodal head samples were not used directly in the transport integration because any flow mass imbalance will cause instability. Thus the head samples were input to VAM3DF to re-compute the steady-state heads. It was observed that the re-computed heads did not differ significantly from the sample values, probably because the SRIF R matrix models the flow equation accurately within the limits of a linear model.

Source uncertainty was treated as linear scaling of the nominal source time profile, which is defined by three coefficients. Thus the effect of source uncertainty was incorporated in post processing using random samples for the scaling factor.

\section{Transport Model}

The numerical grid used for transport was identical to the data fusion flow model grid. The period of investigation was approximately 80 years, from 1956 to 2034. To minimize run- 
time, the model was tested to determine the smallest number of time steps that could be used without affecting the model results. The transport module was executed using 780 time steps and data was output every 36.5 days ( 0.1 of a year).

Mean values of longitudinal dispersivity $\left(\alpha_{\mathrm{L}}\right)$, transverse dispersivity $\left(\alpha_{\mathrm{T}}\right)$, vertical transverse dispersivity $\left(\alpha_{\mathrm{VT}}\right)$, and vertical dispersivity $\left(\alpha_{\mathrm{V}}\right)$ were $20.0,5.0,2.0$ and 2.0, respectively. These dispersivity values were determined as optimum by trial-and-error calibration of the transport model with the measured data (tritium discharged to Fourmile Branch) acquired from WSRC. GeoTrans [4] used an effective porosity of 0.2 for aquifers and 0.3 for aquitards for a GSA groundwater flow model. An effective porosity of 0.25 was utilized for the transport simulations in this study. The apparent molecular diffusion coefficient $\left(D^{\circ}\right)$ was $1.0 \mathrm{E}-06 \mathrm{ft}^{2} /$ day. The distribution coefficient $\left(\mathrm{k}_{\mathrm{d}}\right)$ was assumed equal to zero which translates to a retardation coefficient equal to 1.0 , which is a common assumption for tritium. The decay coefficient was calculated using:

$$
\lambda=\ln 2 / t_{1 / 2}
$$

where $t_{1 / 2}$ is the half life in days. The half life for tritium is 12.3 years. An upstream weighting value of 1.0 was used in the $\mathrm{x}, \mathrm{y}$, and $\mathrm{z}$-directions in the transport simulations.

The transport model had zero initial concentration and zero mass flux boundary conditions for all boundary inflow nodes. After solving for steady-state flow, flux values on the boundary were utilized for determination of boundary conditions. All nodes with positive fluxes (inflow) on the boundary were assigned a mass flux of zero and a volummetric flux equal to the value determined by the flow model. Flach [2] investigated the waste forms deposited in the OBG and developed a tritium discharge model. The Flach model was used to produce time dependent mass flux boundary conditions at 90 nodes, which are in the vadose zone below the OBG. The leaching constant in the Flach model was used to calibrate the transport model to the measured tritium discharge data. The calibrated source model was used as the mean source.

The concentration plumes for the year 1986 were computed using the DFM estimated flow parameters as described above. Figure 8 represents the log normalized concentrations at $\mathrm{x}=3120 \mathrm{ft}$. Another slice, an aerial view, was taken at the $8 \mathrm{th}$ nodal layer from the top and is portrayed in Figure 9.

\section{Tritium Observations}

Tritium concentrations at three observation nodes (Fig. 3) were recorded for each Monte Carlo iteration. Observation node N1 is location on the top of the model near Fourmile Branch. Observation nodes N2 and N3 are $38 \mathrm{ft}$ and $44 \mathrm{ft}$ below the surface, respectively. Both nodes are below the water table and in the path of a tritium plume. The total tritium discharge to Fourmile Branch was also recorded for each Monte Carlo iteration. These simulations results are plotted against actual measured tritium discharges to Fourmile Branch. The simulated discharge of tritium at Fourmile Branch matches remarkably well the measured historical tritium discharge. 


\section{Tritium Plume for 1986 at $\mathrm{x}=3120 \mathrm{ft}$}

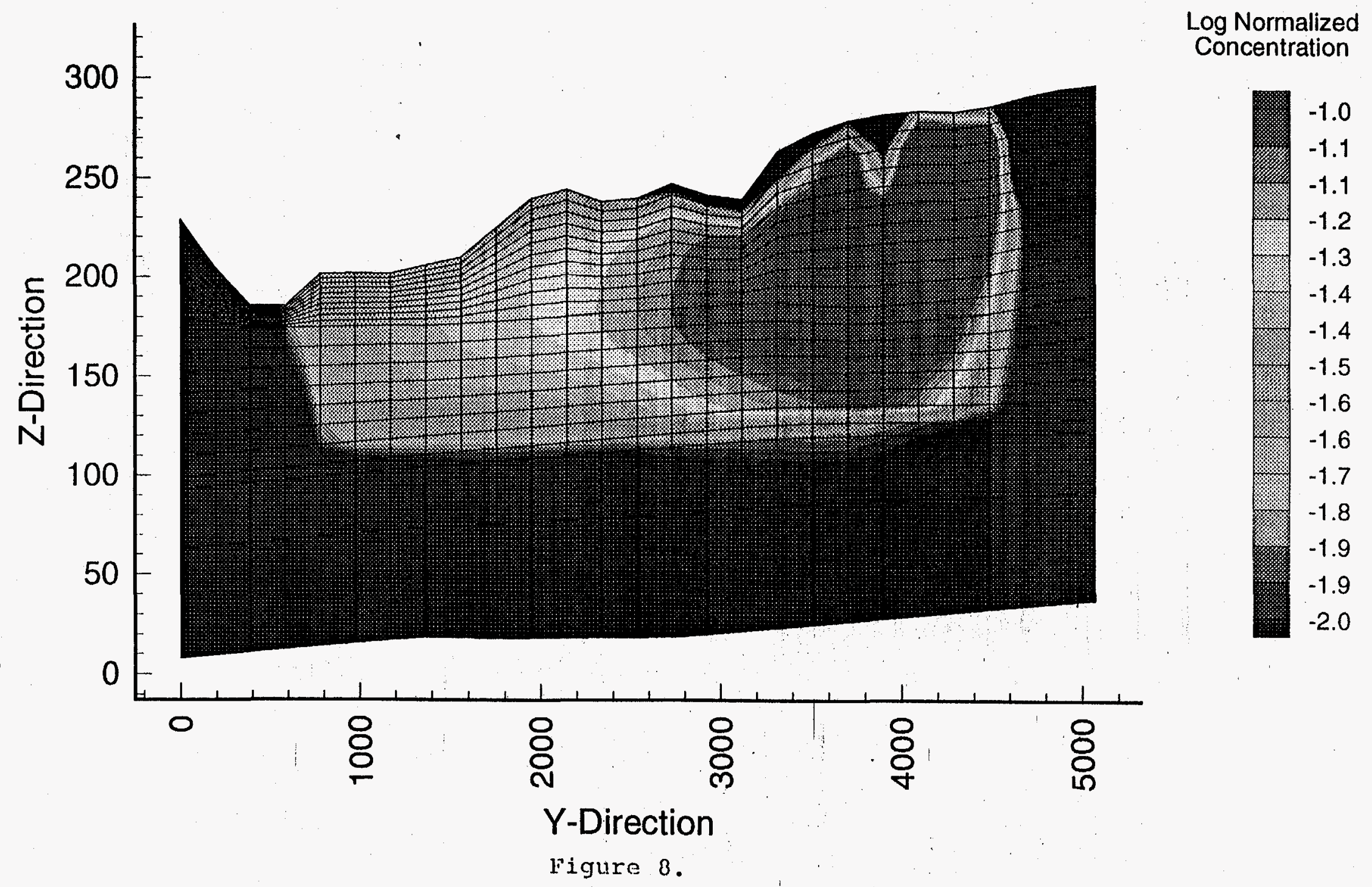




\section{Tritium Plume for 1986 at Nodal Layer 14}

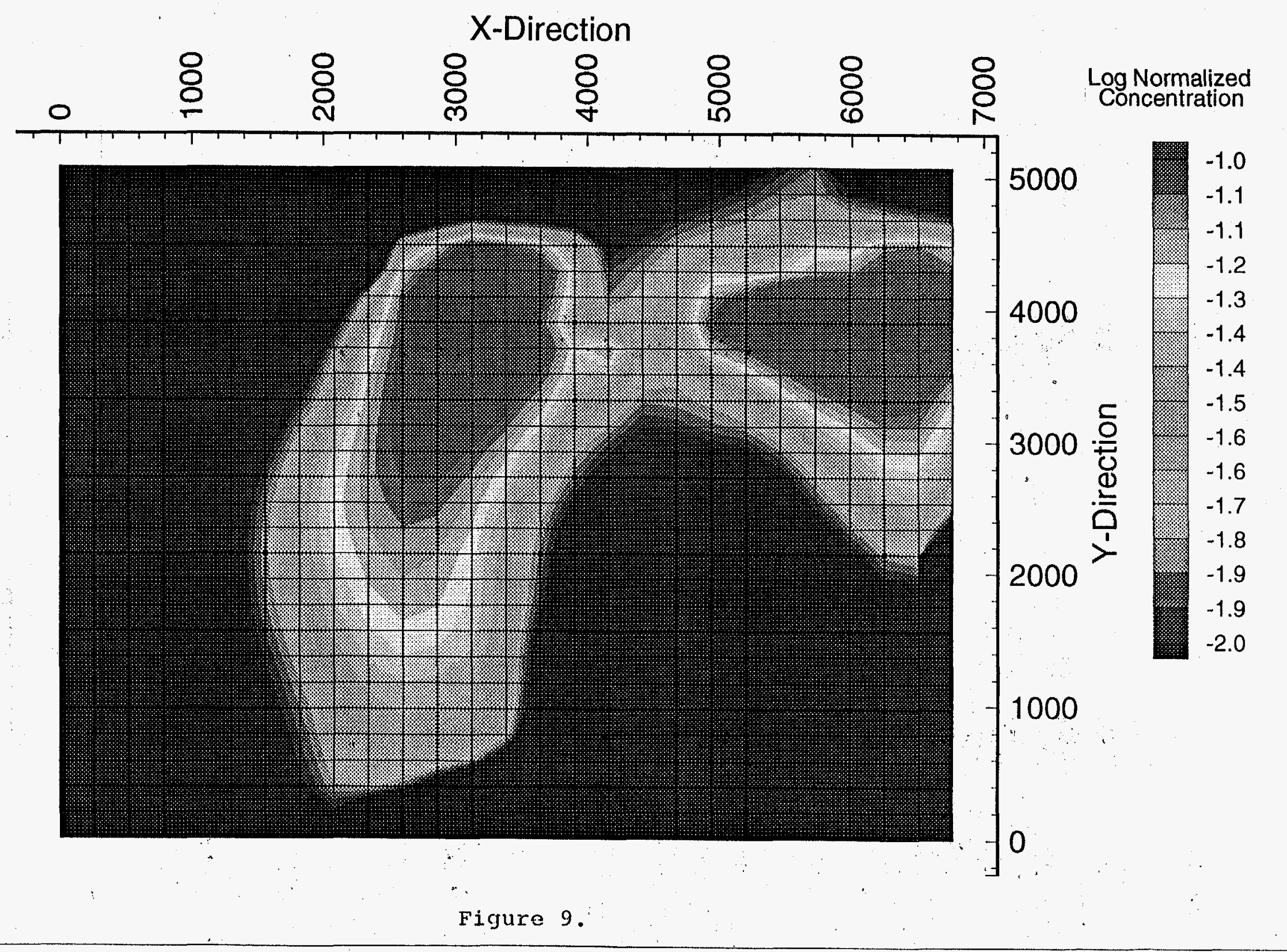




\section{Monte Carlo Results}

Using 1000 Monte Carlo realizations of flow and transport parameters as described above, the distribution of tritium concentration at the observation points was computed. This includes the effect of recharge and conductivity uncertainty. Figure 10 shows a histogram of $\ln \left(\mathrm{k}_{\mathrm{h}}\right)$ at $\mathrm{N} 2$. Note that the conductivity uncertainty. is significant. Source uncertainty was incorporated by scaling the mean source. The source scale factor had a clipped normal distribution between 0.5 and 1.5 with $M=1.0$ and $S D=0.25$. Figure 11 shows a histogram of 1000 realizations of the source scale factor. Since the transport model solves a linear transport equation with linear boundary conditions, the source uncertainty was incorporated by scaling the output concentrations. For each observation node, maximum concentration relative to node $\mathrm{N} 3$ and the corresponding year of inception are as follows:

Table 3. Maximum Concentrations at Observation nodes.

\begin{tabular}{|c|c|c|}
\hline $\begin{array}{c}\text { Observation } \\
\text { Node }\end{array}$ & $\begin{array}{c}\text { Maximum Relative } \\
\text { Concentration }\end{array}$ & Year \\
\hline N1 & 0.0036 & 1986 \\
\hline N2 & 0.7577 & 1977 \\
\hline N3 & 1.0000 & 1977 \\
\hline
\end{tabular}

To construct break through curves for a given confidence bound, the observed concentrations were sorted for each observation time. For each observation time, a concentration was output corresponding to the given confidence bound. Break through curves were determined using confidence bounds of $95 \%, 50 \%$ and $5 \%$ for each observation node. Figures 14, 15, and 16 present the normalized break through curves for N1, N2, and N3, respectively. In addition, break through curves were determined for the tritium discharge to the Fourmile Branch using the same confidence bounds as used for the observation nodes. Figures 12 and 13 show the tritium discharge curves for confidence bounds of $95 \%, 50 \%$, and $5 \%$ superimposed on the field data for recharge/conductivity uncertainty and recharge/conductivity/source uncertainty, respectively. The tritium discharge curves and data in Figures 12 and 13 were normalized with respect to the maximum of the $95 \%$ confidence bound from the recharge/conductivity/source uncertainty. As expected the tritium discharge curves for the recharge/conductivity/source uncertainty deviate from the median confidence bound more than the tritium discharge curves without source uncertainty. 


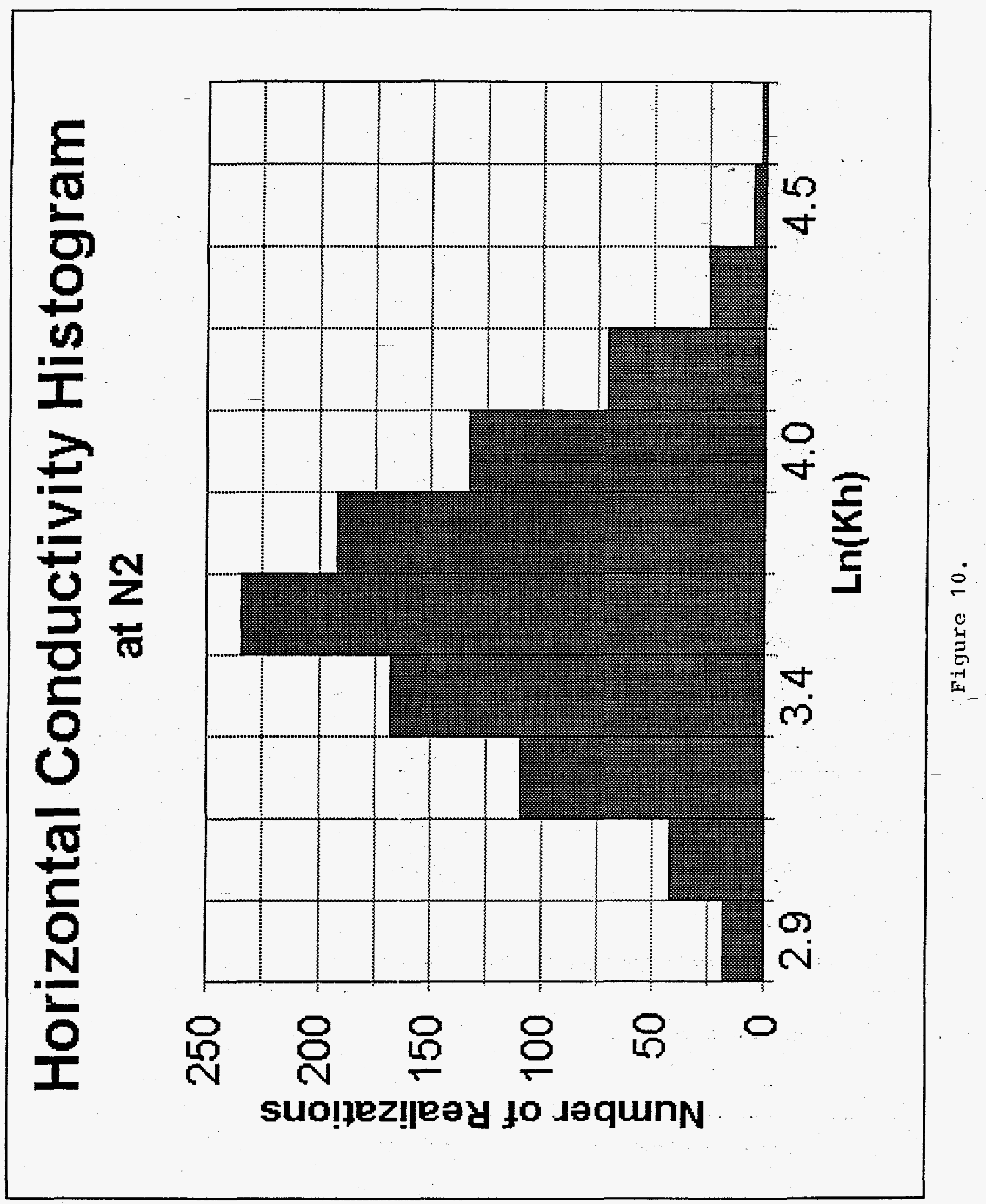




\section{Source Scale Factor Histogram}

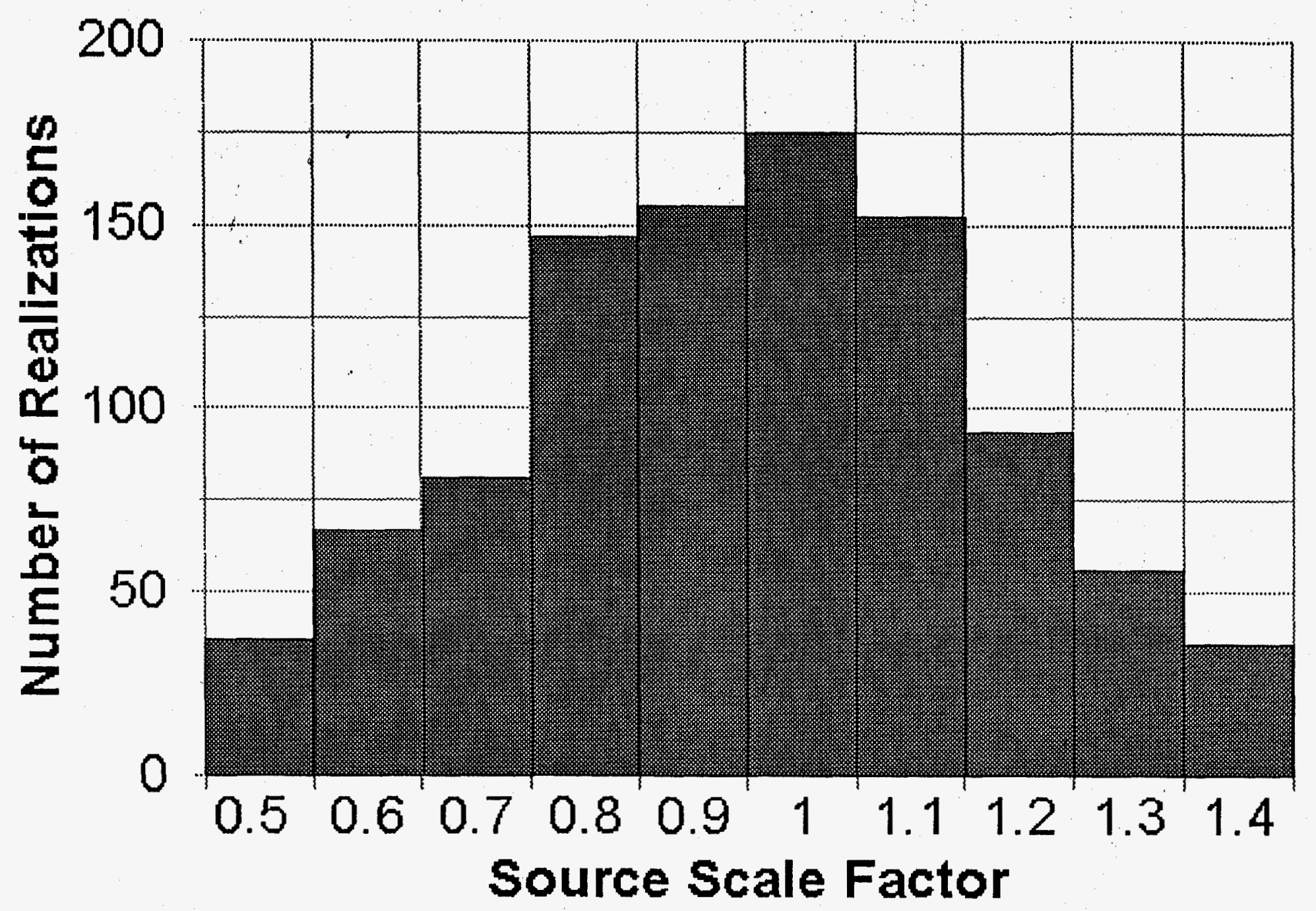


Tritium Discharge to 4-Mile Branch with Recharge and Conductivity Uncertainty

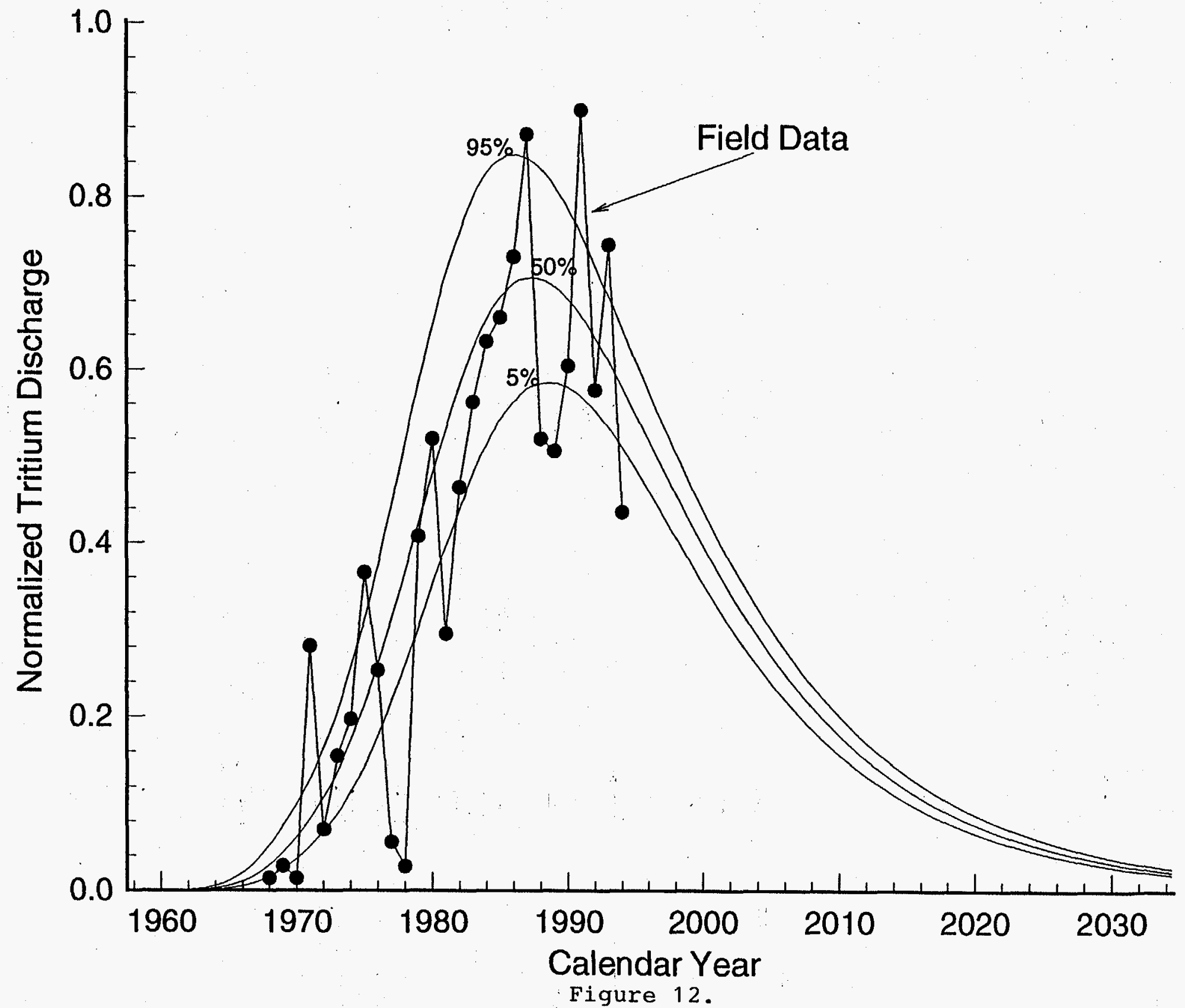




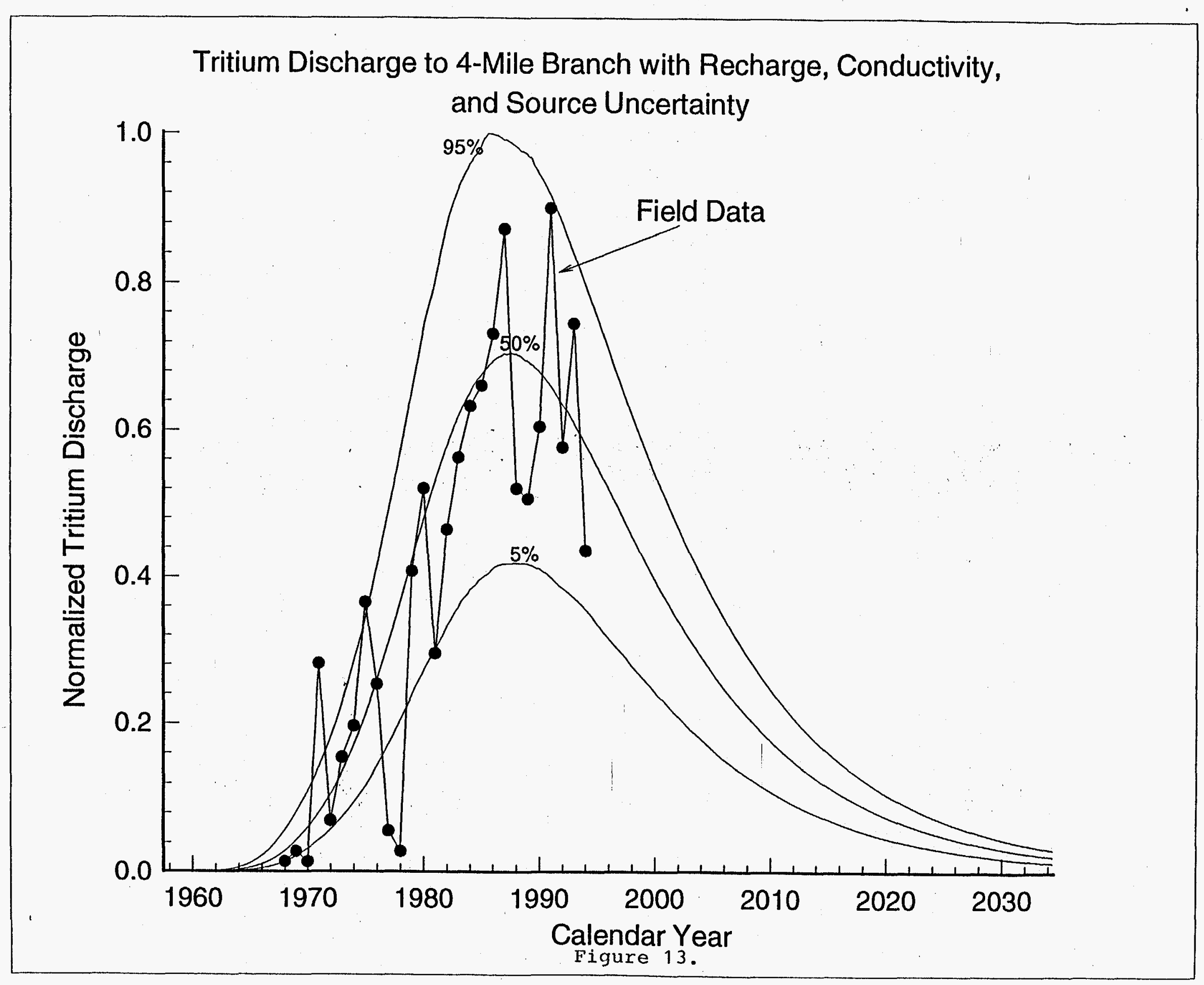




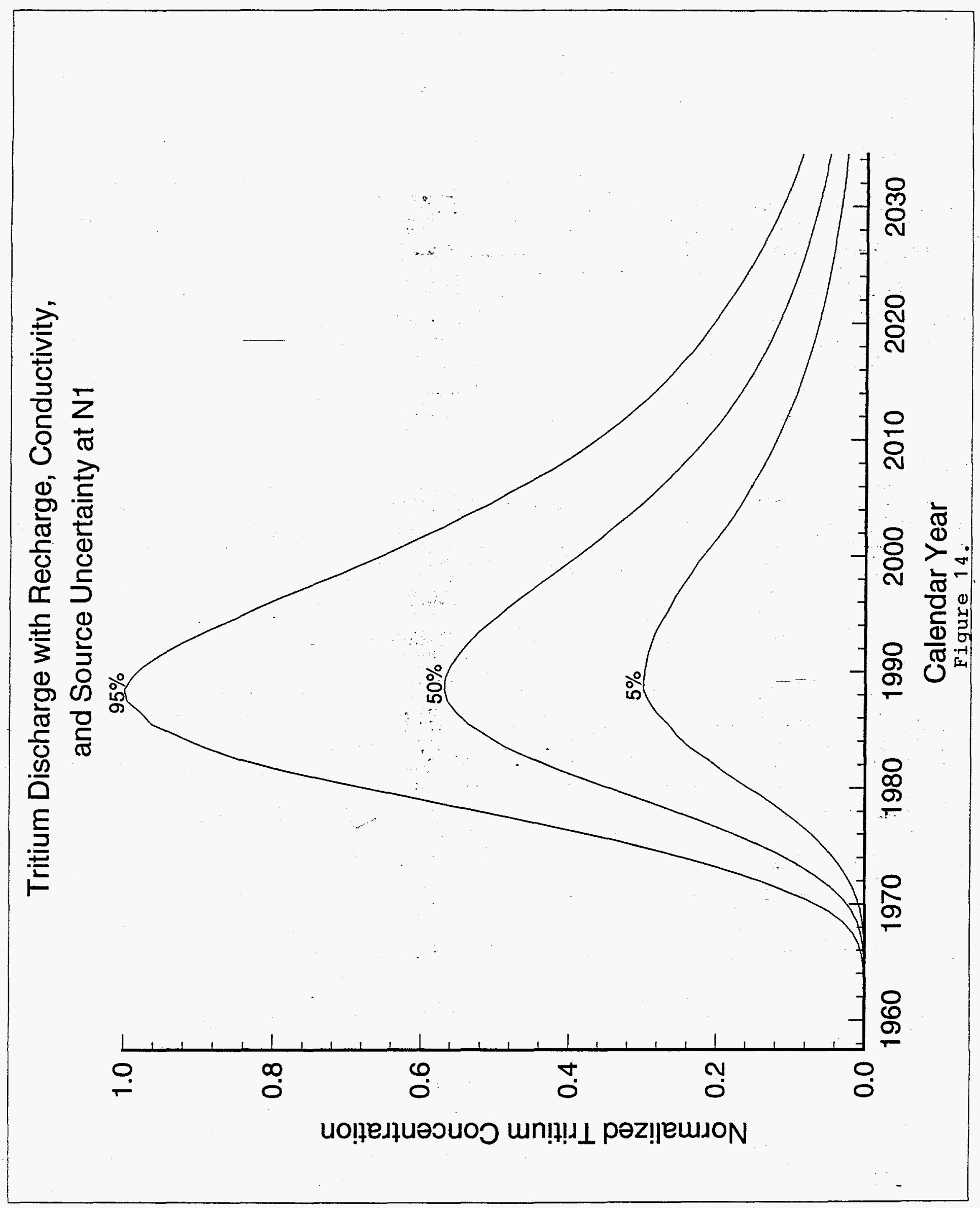




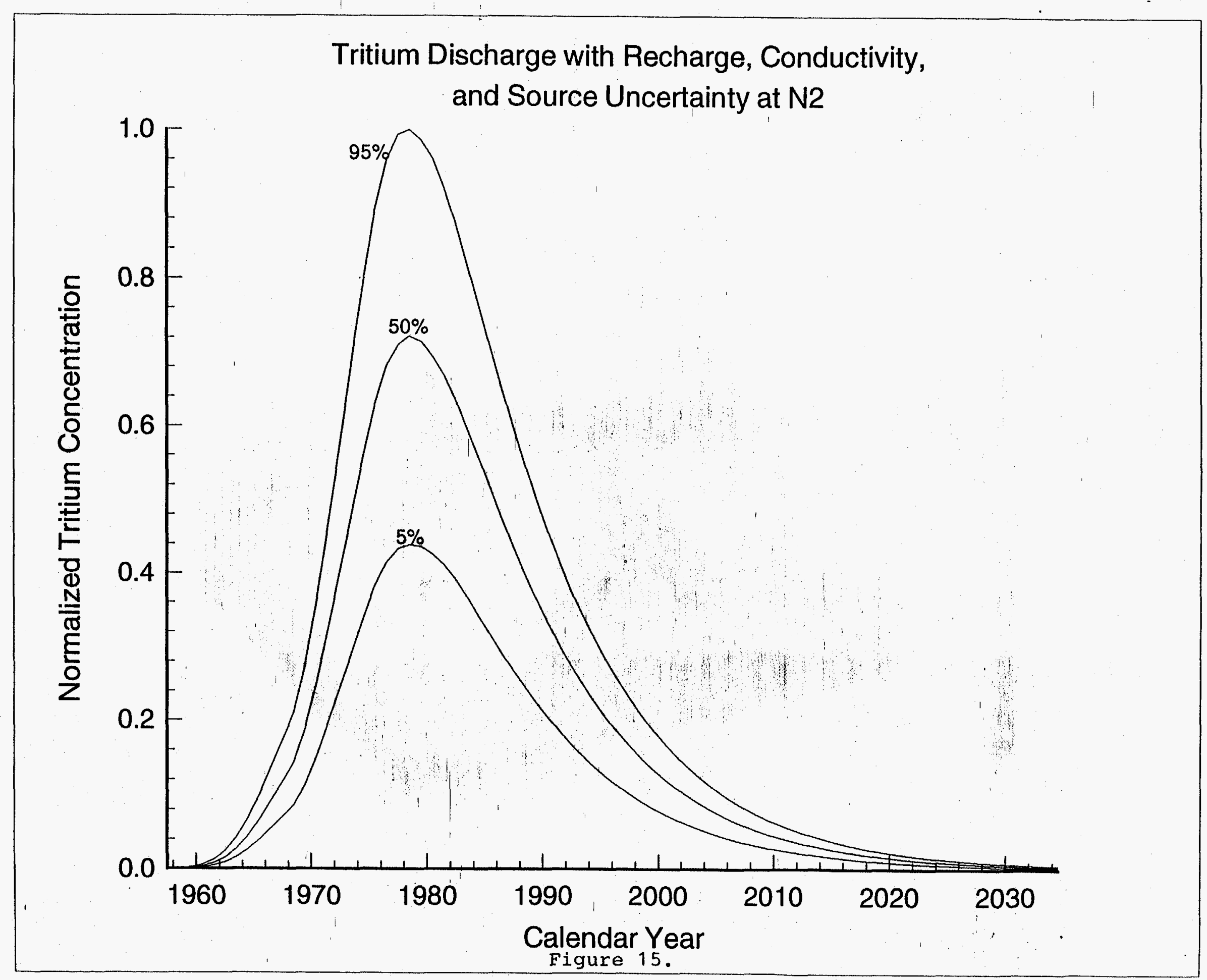




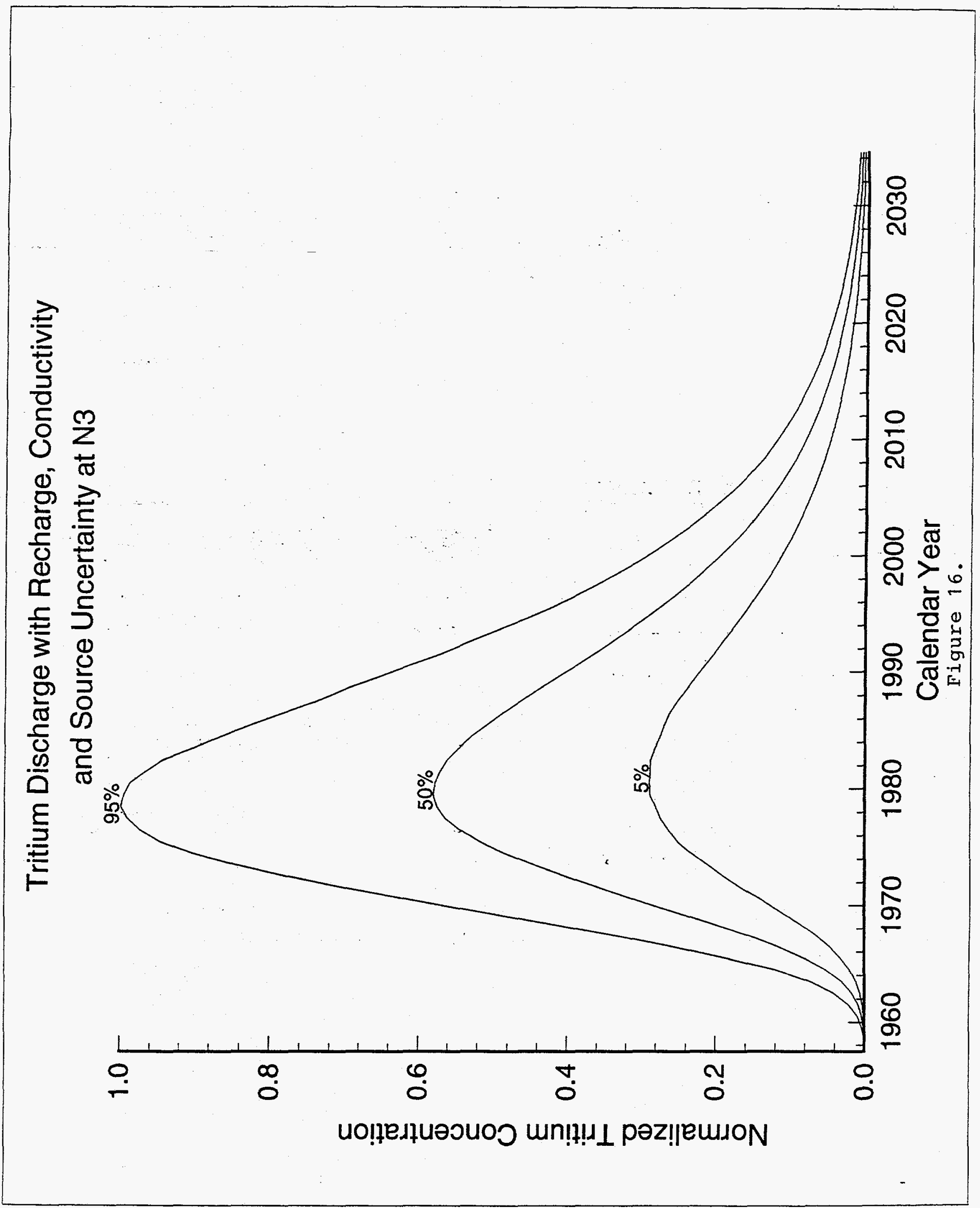




\section{Summary}

The DFM flow model is generally consistent with the previous model of Reference 1 that was obtained using the trial-and-error method. The models have similar pathlines, recharge, and trends in conductivity. The conductivity field for DFM is somewhat smoother, reflecting spatial correlation parameters input to the fusion processing. The spatial correlation parameters are based on hydrogeological judgement and on the fit to the data. The benefits of DFM come mainly from the ability to rapidly combine diverse sources of information to quantify and reduce uncertainty. The specific benefits demonstrated in the work being reported here are the following:

- Quantification of statistical uncertainty in tritium breakthrough curves due to uncertainty in recharge, hydraulic conductivity, and source terms. This shows that uncertainty can be quantified at complex sites such as the OBG, opening the possibility for a more precise level of risk assessment at other sites. Further, this shows that the uncertainty can be quantified in a model that is of sufficient detail to be used for remediation design so safety margins can be quantified.

- Rapid updating of the model. Alternative conceptual models can be rapidly considered in order to get the best final model. This gives the hydrogeologist more control over the modeling process, freed from much of the hand manipulation of the model required by trial-and-error. Further, this means that DFM could be used for on-line model-based monitoring and adjustment of remediation.

- Better Root Mean Square (RMS) fit to the data. The RMS head error for DFM was 1.3 $\mathrm{ft}$ after editing a small number of statistical outliers. The comparable RMS for trial-and-error was $3.0 \mathrm{ft}$. The model also produced a significantly better stream flow prediction, even though measurement of stream flow was not included in the calibration.

\section{References}

[1] WSRC, 1994, "Groundwater flow model for the Old Burial Ground incorporating detailed lithology (U)", draft report.

[2] Flach, G. P., 1994, "Status report on MWMF tritium transport modeling effort", interoffice memorandum.

[3] Flach, G. P., L. L. Hamm, M. K. Harris, P. A. Thayer, J. S. Haselow and A. D. Smits, 1995, "Characterizing hydrogeologic heterogeneity using lithologic data", draft.

[4] GeoTrans, 1993, "Groundwater model calibration and review of remedial alternatives at the F- and H-Area seepage basins", WSRC-TR-93-384. 
[5] Hamm, L. L., S. E. Aleman, W. F. Jones, G. P. Flach, J. S. Haselow, P. S. Huyakorn, S. Panday and T. Birdie, 1995, FACT:Subsurface flow and contaminant transport documentation and user's guide, Westinghouse Savannah River Company Technical Report No. WSRC-TR-95-0223. 